\title{
Design Thinking in Transitional Period
}

\author{
Oğuzhan Özcan* \\ Arçelik Research Center for Creative Industries, Koç University, Istanbul, Turkey
}

In this speculative look of design thinking through the lens of the Renaissance, the author draws our attention to the shocking similarity between the transition in today's world and the Industrial Era. In this comparison, he emphasizes the similar role of "arts in Renaissance" concept and Design Thinking. In this perspective, the author's concern is not about discussing how the Design Thinking process will be in the new era, but just speculating its role as a tool in such a transitional period.

Keywords: design thinking (DT), Renaissance, Industrial Revolution, COVID-19, new era

\section{INTRODUCTION}

\section{OPEN ACCESS}

Edited by:

Diyako Rahmani,

Massey University, New Zealand

Reviewed by:

Michelle Epstein Garland, University of South Carolina Upstate,

United States

Deborah Andrews,

London South Bank University,

United Kingdom

Vusumuzi Malele,

Department of Science and

Innovation, South Africa

*Correspondence: Oğuzhan Özcan oozcan@ku.edu.tr

Specialty section: This article was submitted to Culture and Communication,

a section of the journal

Frontiers in Communication

Received: 26 August 2021 Accepted: 28 January 2022

Published: 08 March 2022

Citation:

Özcan O (2022) Design Thinking in Transitional Period.

Front. Commun. 7:765187. doi: 10.3389/fcomm.2022.765187
I think the complex period that developed with the COVID-19 outbreak is leading to a transition to a new age. Design thinking may be more important in innovation and business development in this transitional period, but I think it may lose importance if a new age arrives (When I say design thinking here, I mean a collaborative problem-solving process to overcome wicked problems; Buchanan, 1992). In this stage, my concern is not about discussing how the design thinking process will be in the new era, but just speculating its role as a tool in such a transitional period.

Actually, it is very difficult to understand this speculation without knowing the historical perspective. In particular, I want to emphasize that if we can understand the transition from Renaissance to Industrial Revolution, we may forecast the future. I want to explain what I mean a little better.

\section{TRANSITIONAL PERIOD TO RENAISSANCE}

What caused the Industrial Revolution? What kind of transition has happened? I especially find it useful to analyze what happened at the beginning of the Renaissance to interpret this:

At the beginning of the fifteenth century, the center of science was Byzantium. Byzantine scholars had the advantage of learning from the works of scientists and philosophers who laid the foundations of scientific research in the past and developed ancient Greek thought. Therefore, they were scientifically at the forefront of the world (Runciman, 1970, p. 87). The use of Arabic as the language of science in the Ottoman Empire, which was the greatest state power of that period, also influenced this. At that time, science in the Arabian Peninsula was very advanced. Byzantine scientists took many elements from Arabs to support modern science, especially mathematics and accelerated their scientific development (Kümin, 2017, p. 173).

On the other hand, as the Roman Church increased pressure, Europe realized that something had to be done to stand against the expansion of Islamic influence (Berger, 2014). Their most significant advantage was Ottoman Empire's abstinence from science at that time. They often destroyed the incoming innovations and declared them illegal, fearing that these scientific advancements would destroy the empire's authority. For instance, the printing press was prohibited in 1,485 to protect the domination of calligraphy artists (Stark, 2014, p. 42). Overall, such concerns prevented scientific development in the Ottoman Empire. 
After the conquest of Istanbul in 1,453, many scientists in Byzantium felt obliged to leave Istanbul, mainly because of the Christian world's fear of Islam (Thomas and Chesworth, 2018, p. 11). They shortly found themselves in Rome, Italy (Runciman, 1970). The mindset they encountered in Europe especially in the Protestant approach was more liberal. In this respect, the arrival of scientists who escaped from Byzantium triggered an enlightenment period, a liberal model; therefore, an explosion of scientific production occurred. Many discoveries occurred during this period, such as the evaporation of water at 100 degrees Celsius, research on astronomy (Merriman, 2009, p. 293), the establishment that the world is round, universal gravitation and progress in human anatomy studies (Kümin, 2017, p. 261).

This transition starting from the Middle Ages until the enlightenment period roughly took around 3,000 years (Stearns, 2010).

\section{THE ROAD FROM RENAISSANCE TO INDUSTRIAL REVOLUTION}

The term Renaissance usually recalls Leonardo Da Vinci's paintings. However, we must consider Renaissance within that period, not with today's mindset. The Arts of that time did not actually mean arts. Arts with the holistic perspective of that time, had an aesthetic sense of value (Conrad, 2014). Philosophers such as David Hume took a different view, including philosophy, and refused the official rules in art as the royal academies or religion heavily influenced them.

In this context, the idea of an ideal person who is competent in many subjects as a Universal person or a Renaissance man began to emerge (Merriman, 2009, p. 60). Leonardo $\mathrm{Da}$ Vinci worked in such an interdisciplinary manner and was seen as a reflection of the Renaissance man (Merriman, 2009, p. 60). Historians assert that Leonardo Da Vinci's machines, anatomy drawings, and innovations he introduced to science and art were unexpected new outputs (Merriman, 2009, p. 61). Like Da Vinci, the scientists of that period looked at science from a holistic perspective that integrated sciences and arts. Thanks to this perspective, many different inventions and views that transformed life in the West were able to emerge.

For instance, the printing press was discovered in the fifteenth century by Johannes Gutenberg in Germany (Merriman, 2009, p. 34). The printing press encouraged new forms of cooperation between science and art. For example, anatomical paintings painted by artists were distributed to the whole world with the development of the printing press (Kümin, 2017, p. 244). As the way of spreading knowledge cleared, European societies started to move from the scholastic perspective of the Middle Ages to the era of enlightenment. Technological inventions affected the economy and caused a socioeconomic change in societies (Brown, 2009). During this period, the bourgeois class was rising which largely consisted of economically independent businessmen (Gill, 2008, p. 29). This financial freedom enriched the bourgeois class. The enriched bourgeois class gave scientists freedom and the right to research (Heller, 1981, p. 149). Thus, there was a transition from the feudal structure to a new social structure.

Meanwhile, new continents were discovered. New mineral resources (e.g., gold, silver, diamond) were found (Brotton, 2004, p. 130). The enlightenment period in Europe, in conjunction with the discovery of new continents, caused colonialism to emerge. Processing and sending minerals back to where they were found became the new trade model. With the new capabilities of processing mineral resources, new payment methods started to emerge. For example, as an achievement of rapidity in marketing, the extracted gold and silver resources enabled the development of global currencies along with the increase in trade (Brotton, 2004, p. 44; Stearns, 2010, p. 65; Kümin, 2017, p. 208).

In the meantime, the search for a place that allowed fastermechanized production started, especially since textile production by hand was insufficient. This need triggered factories to emerge. The first factory in the world is considered the silk factory by Thomas Lombe in Derby, England, in 1,721 (Powell, 1984). This was the beginning of the Industrial Revolution.

\section{VITAL CHANGE AND THE EMERGENCE OF PROFESSIONAL DESIGN WITH THE INDUSTRIAL REVOLUTION}

The transitional period from Renaissance to Industrial Revolution revealed a new awareness in human beings, whereas the Industrial Revolution unveiled a new lifestyle.

What were the outcomes of the Industrial Revolution? A new life emerged; it became necessary for the workers to live close to their factories since they had to work faster. People were removed from the large family structure and forced to work for long hours, days or even weeks without giving a break (Thompson, 1967). They took part in making simple shelters. In the eighteenth and nineteenth centuries, especially in England, these people lived in these shelters and worked in jobs with unimaginable conditions. A new life plan was needed for this situation. People revolted to improve their quality of life and demanded newly designed houses to live more comfortably as a nuclear family. This was a lengthy and painful process. Big residential buildings were transforming into places where nuclear families could live (Plunz, 2018, p. 55). The basis of the lifestyle we live today was founded in the nineteenth century. The role of design professionals was essential in this change.

In the old school design practice, dictation, which imposes individuals how to live and what to use through artifacts, was necessary for design professionalism. In fact, this professionalism is still adopted by some designers. Although a much more democratic and user-centered approach is on the rise in the design field, some designers may still strongly value dictation. Those who still value dictation embrace a mission in culture to introduce people different flavors. However, the designer's mission is not only to have us experience new things but also to 


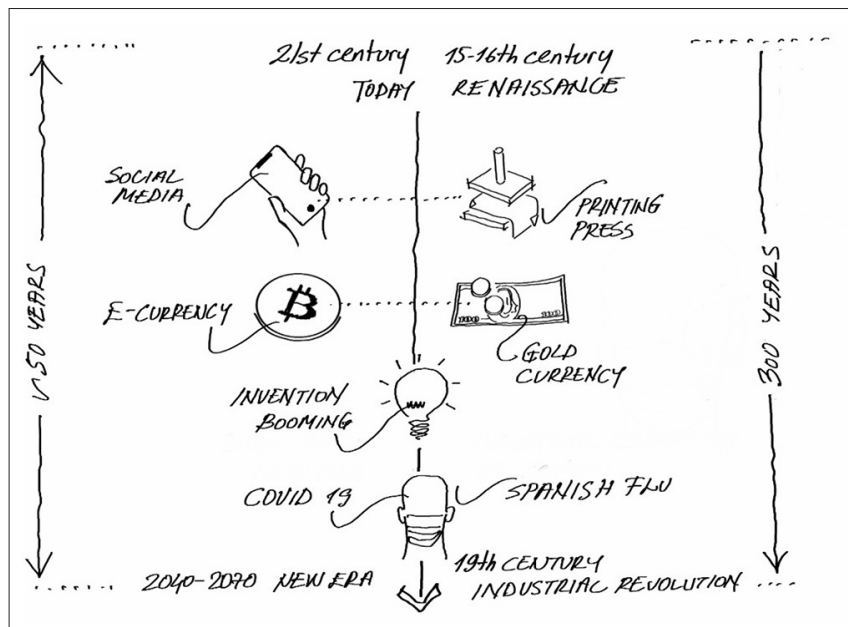

FIGURE 1 | Similarities on the ERA transition.

make us think, to provoke us to go beyond the ordinary when necessary.

With this perspective, we shall look at the famous French designer Philippe Starck's lemon squeezer (Philippe Starck. Juicy Salif Lemon Squeezer. MoMA, 1988). This is not the archetypical lemon squeezer that we are familiar with. Philippe Starck envisioned a brand-new lemon squeezer for Alessi. This lemon squeezer is not considered useful; it splatters all over the place when you squeeze a lemon with it. However, it offers a change in behavior and is considered innovative. Alessi produced 550,000 pieces of this product (Woods et al., 2011), but it is not used today. Up to 10,000 gold versions of this product are available in museums and collections only (Aurisicchio et al., 2013). Strack's design is a good contemporary example of the designer's dictation.

This design culture of teaching the dictation of design and lifestyle became predominant, especially with the Bauhaus school (Droste, 2002, p. 6). Today, in design schools with traditional devotion, "You will orient the society." is the most cliché saying young designers often hear.

\section{THE SHOCKING SIMILARITY BETWEEN THE TRANSITION IN TODAY'S WORLD AND INDUSTRIAL TRANSITION}

What kind of transition is present today? When we look at the past 20 years, it may be surprising to see that the transition steps in the Renaissance and the Industrial Revolution are almost the same. Their stories are also similar (Figure 1). What is this similarity?

Suddenly, a concept called the internet entered our lives in the 2000s. In other words, an innovation impacted our daily lives, similar to the time when the printing press was invented. Although, the internet was something that emerged in the 1960s with ARPANET (Hauben and Hauben, 1998; Ryan, 2010, p. 26).
After 20 years, the internet became an indispensable part of our lives along with the emergence of social media platforms.

Although there may be those who do not use social media due to objection, social media is a platform in which we spend approximately 3-4h every day. I believe there is no one who does not devote time to social media. With the growth of social media, the concept of individualism started to emerge, especially in Generation Z. Today, everyone can make a public broadcast of their own. Social media reinforces people's desire to become famous and share where they go and what they do in a day. In my opinion, for Generation $Z$, a more individual lifestyle may be observed as they leave their nuclear family. As a result of living individually and the influence of social media, Generation $Z$ may start to demand more personalized products, designed especially for them.

On the other hand, we encountered another fact in 2009 with Bitcoins (Zheng et al., 2017). Bitcoins, which are unlimited, tax-free, and of an unknown owner, emerged as a brand-new trading tool (Surprisingly, seventeenth-century gold and silver began to be widely used as intermediaries in the world). Lately, Generation $Z$ has been showing great interest in Bitcoins. The usage of this currency and how it is going to be taxed are still not certain; governments are looking for ways to get these aspects under control. Bitcoins are not currently under the control of national structures, and users still consider them as an unsafe tool (Alshamsi and Andras, 2019). It is still unknown if Bitcoins will be a move toward a tax-free life. Yet, new advancements in quantum technology and the shrinkage of transistor sizes (Moore, 1965) may create safer cryptocurrency systems. Therefore, if we trust these systems, our ways of trading may change drastically. We already see the traces of this. For instance, during the COVID19, pandemic consumers demanded safer ways to shop. Thus, we witnessed the transition of many brands adapting numerous contactless payment systems. I believe this might be one of the initial steps toward transitioning our ways of trading.

People did not care much about artificial intelligence initially, which started to be developed before 2014. As computers are getting faster, artificial intelligence has rapidly become a part of our lives since 2015. Due to the growth of artificial intelligence, and automation in the industry, future jobs are at risk of vanishing (Zhu, 2004; OECD, 2017, p. 10). Artificial intelligence may also increase the structuring of our preferences. Its advancement may entail product concepts that are more aware of the user's needs and expectations before they even know it. Thus, more smart product concepts may emerge.

When we combine the developments since the 2000s, it would be fair to argue that we have entered a brand-new communication era. Similar to how the printing press was found and transformed our lives. As in the Renaissance, (i.e., enlightenment period), science is getting more widespread today.

Surprisingly, the 1918 Influenza Pandemic emerged right after the Industrial Revolution, and wars arose along with the epidemic. It is an interesting coincidence that today we encounter a similar extraordinary epidemic like the COVID-19 outbreak. Based on this similarity, I wonder if there will be any similarities between the contributions of these two critical events to the historical transition to be considered. 


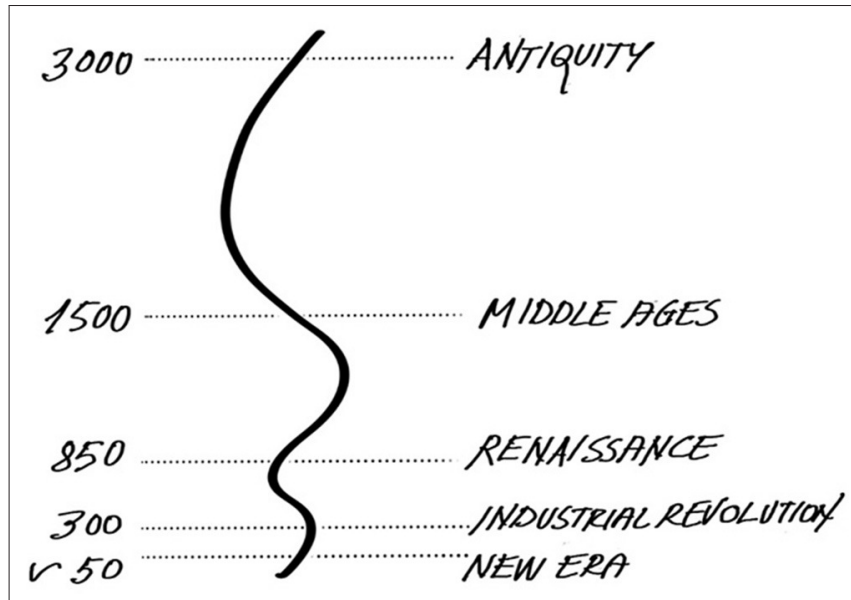

FIGURE 2 | Periods of ERA transition.

\section{WHEN WILL WE ENTER A NEW ERA?}

What we study on recent research also state that historical transition is faster than in previous eras:

Three hundred years are taken into consideration when we talk about the transition from the Renaissance to the industrial era. When we look at the earlier transition (from Medieval to Renaissance), we take 850 years into account. The transition from the ancient age to the Middle Ages happened between 1,000 BC-500 AD, about 1,500 years, a more extended period. The transition from Bronze Age to the First Age takes about 3,000 years, which is much longer (Stearns, 2010, p. 20). In other words, the long-term transitions evolve into transitions that take shorter years (Figure 2).

According to one view, with every invention that has a radical impact on our lives, the new invention's transition is shortened by 10 years (Theis and Wong, 2017). Further, $80 \%$ of the world's inventions have been made in the last 10 years (Koomey et al., 2010, p. 3). Therefore, there is an impression that a transition will take place much sooner than the previous one.

Well then, while there has been a 300-year transition from Renaissance to Industrial Revolution, will the pace of the inventions made between the years 2000 and 2020 continue? In how many years will we enter a new era?

The possibility of completing an era in 2040-70, whether it is possible to utilize dictation again instead of making decisions with collaborative thinking, also known as design thinking, and whether large firms may create a new feudal structure is among the topics that are always discussed.

For instance, in the future, I wonder if global social media and e-commerce platforms that are recalled as the most popular brands can impose consumers new behaviors and habits? If this assumption happens, will we witness more centralized product marketing communication tools?

Moreover, if it is to occur it is another matter of curiosity how this company-based feudal structure may be shaped by shared verification in the society that emerged with cryptocurrencies.
Different resources made different predictions about this transition. For example, according to one view, there may be a big change in every field from economy to technology in 2050 (Franklin and Andrews, 2012). While another view states that technological developments will peak in 2036 and our lives will start to change in the 2040s (Brian and Euel, 2016).

\section{THE IMPORTANCE OF DESIGN THINKING IN THE TRANSITION WE ARE GOING THROUGH}

As I mentioned at the beginning, my purpose in this speculation is to emphasize that design thinking will be an actor of the transitional period, not to manifest methods to apply it. If the above speculation happens then I believe, design thinking will lose importance and we might again fall back into the dictation of design in the new era.

I feel very lucky because I will be able to retire and go fishing in 5-6 years. However, it seems that the coming years will be a little painful for Generation Y. I think Generation $Z$ will also suffer in 2040s. There may be other new technological inventions that will change our lives. There may also be brand-new epidemics, wars at a great scale. Therefore, the more Generation $Z$ adapts itself to this changing environment with design thinking philosophy, the more easily they can manage the chaos that will occur.

Why is this important? In the next $10-15$ years, those in Generation $Z$ who do not adapt to the design thinking models and continue with the old disciplinary logic may lose the competition in their career development. We must think both like an engineer and as an artist like it was in the Renaissance, in the discipline of collaborative thinking (Brown, 2009).

Overall, for designers or design thinkers in Generation $Z$ to undergo this process without being harmed, they must perceive the new logic and receive training accordingly in this transitional stage. This is highly important to develop new products, tools, systems, or innovative processes to tackle emerging complex and wicked problems of the new era. For this reason, everything may be different for them, which goes beyond the ordinary ways of thinking, has a collective thought, produces ideas, and can say "This is possible." without saying "Is this really possible?". If we look at what we have been going through for the last 1.5-2 years, we cannot foresee what we will experience in the next 5-6 years. The years ahead may be even more turbulent, I do not know in which direction the world will go. However, if the designer and design thinkers in Generation $Z$ consider all possibilities, they can come out with a big gain. Therefore, we must go beyond the ordinary way of design with design thinking, in this stage.

I must assert that this is an opinion piece, that aims to trigger discussions for how Design Thinking might take place in the transition to a new era. Although this article is not based on a robust methodology, it triggers researchers to think about possible futures. For instance, what circumstances we may encounter if we succeed or fail to adopt AI could be examined further. In the scope of COVID-19, future research may collect rigorous data on topics such as the use of AI in vaccine development, or how governments use data to put lockdowns in action. How Design Thinking plays a role in 
such transitions could be explored. To conclude, based on the discussion points this article raises, I find it a valuable opinion piece raising awareness for future possibilities exploring the role of Design Thinking.

\section{DATA AVAILABILITY STATEMENT}

The original contributions presented in the study are included in the article/Supplementary Material, further inquiries can be directed to the corresponding author/s.

\section{AUTHOR CONTRIBUTIONS}

The author confirms being the sole contributor of this work and has approved it for publication.

\section{REFERENCES}

Alshamsi, A., and Andras, P. P. (2019). User perception of Bitcoin usability and security across novice users. Int. J. Hum. Comput. Stud. 126, 94-110. doi: 10.1016/j.ijhcs.2019.02.004

Aurisicchio, M., Bracewell, R. H., and Armstrong, G. (2013). The function analysis diagram: intended benefits and coexistence with other functional models. Artif. Intel. Eng. Design Anal. Manufact. 27, 249-257. doi: 10.1017/S0890060413000255

Berger, M. (2014). A Brief History of Islam in Europe. Leiden University Press. doi: $10.24415 / 9789087281953$

Brian, B., and Euel, E. (2016). The surprise that transforms. an American perspective on what the 2040s might bring. Soc. Evolut. History 15, 82.

Brotton, J. (2004). The renaissance bazaar: from the silk road to michelangelo. Engl. Hist. Rev. 119, 795-796. doi: 10.1093/ehr/119. 482.795

Brown, T. (2009). Change by design. Harper Collins. 4, 143-144. doi: 10.1163/9789004394827_018

Buchanan, R. (1992). Wicked problems in design thinking. Design Issues 8, 5-21.

Conrad, L. (2014). Integration and the liberal arts: a historical overview. Horizon 22, 46-56. doi: 10.1108/OTH-11-2013-0045

Droste, M. (2002). Bauhaus, 1919-1933. Berlin: Taschen.

Franklin, D., and Andrews, J. (2012). Megachange: The World in 2050, Vol. 105. Hoboken, NJ: John Wiley and Sons.

Gill, G. (2008). Bourgeoisie, State, and Democracy: Russia, Britain, France, Germany, and the USA, Vol. 148. New York, NY: Oxford University Press.

Hauben, M., and Hauben, R. (1998). Behind the net: The untold story of the ARPANET and computer science. First Monday 3. doi: 10.5210/fm.v3i8.612

Heller, A. (1981). Renaissance Man. Trad. de Richard E. Alien. New York, NY: Schocken Books.

Koomey, J., Berard, S., Sanchez, M., and Wong, H. (2010). Implications of historical trends in the electrical efficiency of computing. IEEE Ann. Hist. Comput. 33, 46-54. doi: 10.1109/MAHC.2010.28

Kümin, B. (2017). The European World 1500-1800: An Introduction to Early Modern History. London: Routledge.

Merriman, J. (2009). A History of Modern Europe: From the Renaissance to the Present, Vol. 1. New York, NY: WW Norton \& Company.

Moore, G. E. (1965). Cramming More Components Onto Integrated Circuits. New York, NY: McGraw-Hill.

OECD (2017). Future of Work and Skills. Paris: Organisation for Economic Co-Operation and Development.

Philippe Starck. Juicy Salif Lemon Squeezer. | MoMA (1988). Available online at: https://www.moma.org/collection/works/1825 (accessed October 3, 2021).

Plunz, R. (2018). A History of Housing in New York City. New York, NY: Columbia University Press.

\section{ACKNOWLEDGMENTS}

I especially thank Yağmur Kocaman for her support in editing this article. I would also like to acknowledge my lab team, Ceylan Beşevli, Taylan U. Bulut, Cansu Çetin Er, Hayati Havlucu, Vendi Havlucu, Ege Keskin, Berk Göksenin Tan, and Ozan Yildirim for their encouragements to write this opinion piece. Finally, this work is inspired by my daughter Ecesu's words during her studies about the history of Renaissance.

\section{SUPPLEMENTARY MATERIAL}

The Supplementary Material for this article can be found online at: https://youtu.be/bs9r66QBkN8

Powell, K. (1984). I. Industrial building in retrospect. J. R. Soc. Arts 133, 16-30. Runciman, S. (1970). The Last Byzantine Renaissance. London: CUP Archive.

Ryan, J. (2010). A History of the Internet and the Digital Future. London: Reaktion Books.

Stark, R. (2014). How the West Won: The Neglected Story of the Triumph of Modernity. Wilmington, DE: Open Road Media.

Stearns, P. N. (2010). World History: The Basics. London; New York, NY: Routledge.

Theis, T. N., and Wong, H.-S. P. (2017). The end of moore's law: a new beginning for information technology. Comput. Sci. Eng. 19, 41-50. doi: 10.1109/MCSE.2017.29

Thomas, D., and Chesworth, J. (2018). "Christian-muslim relation: A bibliographical history Vol. 12. Asia, Africa and the Americas (1700-1800)," in The History of Christian-Muslim Relations, Vol. 36. doi: $10.1163 / 9789004384163$

Thompson, E. P. (1967). Time, work-discipline, and industrial capitalism. Past Present 38, 56-57.

Woods, A. T., Poliakoff, E., Lloyd, D. M., Kuenzel, J., Hodson, R., Gonda, H., et al. (2011). Effect of background noise on food perception. Food Qual. Prefer. 22, 42-47. doi: 10.1016/j.foodqual.2010.07.003

Zheng, Z., Xie, S., Dai, H., Chen, X., and Wang, H. (2017). “An overview of blockchain technology: Architecture, consensus, and future trends," in 2017 IEEE International Congress on Big Data (BigData Congress) (Honolulu, HI: IEEE), 557-564.

Zhu, Q. K. (2004). “Design perspectives", in Power Distribution Network Design for VLSI (John Wiley and Sons), 33-73. doi: 10.1002/047166 0302.ch2

Conflict of Interest: The author declares that the research was conducted in the absence of any commercial or financial relationships that could be construed as a potential conflict of interest.

Publisher's Note: All claims expressed in this article are solely those of the authors and do not necessarily represent those of their affiliated organizations, or those of the publisher, the editors and the reviewers. Any product that may be evaluated in this article, or claim that may be made by its manufacturer, is not guaranteed or endorsed by the publisher.

Copyright (C) 2022 Özcan. This is an open-access article distributed under the terms of the Creative Commons Attribution License (CC BY). The use, distribution or reproduction in other forums is permitted, provided the original author(s) and the copyright owner(s) are credited and that the original publication in this journal is cited, in accordance with accepted academic practice. No use, distribution or reproduction is permitted which does not comply with these terms. 